\title{
SALES PROMOTION ACTIVITIES - EFFECTIVE TOOL OF MARKETING COMMUNICATION MIX
}

\author{
E. Genchev*, G.Todorova \\ Faculty of Economics, Trakia University, Stara Zagora, Bulgaria
}

\begin{abstract}
A highly competitive environment is forcing sellers constantly using different marketing tools and strategies to win new clients and thereby increase their profitability. Sales promotion is one of the best tools to attract new customers and retain old ones, including marketing activities by adding more value to the products for a limited period of time in order to stimulate consumer purchases and effectiveness of intermediaries. For the purpose of the study were interviewed 60 men and women, aged 18 to 64 years by detailed a questionnaire. The study confirms that sales promotion is an effective instrument which has a positive direct impact on users purchase behavior. From the answers became clear that all types and instruments of sales promotion performing on consumers as $21 \%$ would certainly buy more than $59 \%$ of respondents probably would benefit from product promotion. Most frequently used communication channels for achieving information about various promotional activities by the user are the Internet with $82.5 \%$ and promotional brochures with $77.2 \%$.
\end{abstract}

Key words: sales promotion, effectiveness, promotional activities

\section{INTRODUCTION}

A highly competitive environment constantly forces sellers to use different marketing tools and strategies to win new customers and thereby increase their profitability. Sales promotion is one of the best tools for attracting new customers and hold the old customers including marketing activities to add product value for a limited time, to stimulate consumer purchases and the effectiveness of intermediaries [1]. This tool of the promotional mix helps not only builds customer loyalty to the brand but also leads to increased sales. In order to survive in the current situation of serious competition, sellers also use other marketing activities such as advertising, public relations, personal sales, direct marketing.

Objectives of the study:

1. Present the main types and instruments of sales promotion.

2. Identify which ones are known to consumers, where they get information about sales promotion and are most often used by them.

3. Analyse the effect of these promotional activities on different product types.

\footnotetext{
*Correspondence to: Assoc. Prof. Evgeni Genchev, PhD, Faculty of Economics, Trakia University, Stara Zagora, Bulgaria, , E-mail: evg_gen2000@abv.bg
}

Sales promotion is one of the promotional mix elements, its a technique impacting the buyer through personal communication and a system of market instruments to provoke or accelerate the purchase with short-term effect. It includes marketing activities to add product value for a limited amount of time in order to stimulate consumer purchases and intermediary performance. Sales promotion consists of a variety of tools, usually short-term, designed to promote faster and/or greater purchase of certain products or services by buyers or sellers [2].

According to Palmer [3] sales promotion is distinctive, they offer additional incentive to buy. Gilbert and Jakarta [4] point out that sales promotion consists of extremely varied shortterm promotional tools designed to generate the desired response from customers. The growing interest in the sales promotion ' use as marketing tactics has led to an unparalleled growth of research in this area.

According to J. Stiincamp [5] sales promotion helps increase consumer sensitivity, trigger switching between brands, creates commodity samples that further enhance the brand's popularity. Sales promotion usually lowers the price of products for a larger purchased quantity. As a result, it improves the customerperceived value of the product price leading to 
the purchase decision initiative. Sales promotion measures are geared to achieving quick results, but they have to be combined with other instruments to increase sales.

\section{RESULTS AND DISCUSSION}

In order to collect the survey information, a questionnaire was developed to interview 60 respondents from 18 to 64 years old men and women. The survey contains personal and demographic variables in order to get more data about the respondent, such as gender, age, income, a number of members of the household. As well as research key questions and related to the knowledge of the types of sales promotion, their frequency of use and their effectiveness across product types.

The survey respondents who completed the survey are 57. The majority of respondents are $52.6 \%$ of the respondents in the age group 2534. Regarding the gender classification $59.6 \%$ of respondents are women and the other $40.4 \%$ are men.
GENCHEV E., et al. Analysis of sales promotion effect to consumers

\section{The level of awareness of sales promotion among consumers.}

Awareness is sales promotion technique that consumers recognize as a marketing communication tool. Awareness is a prerequisite to build respect and create a plan to purchase. One of the tasks of the study was to establish consumer awareness of sales promotion techniques and methods. The survey included the following types:

- Sampling

- Coupons

- Premiums - Goods in a package

- Discounts

- Goods in extra / additional product, quantity /

- Contests, lotteries, games

In Figure 1 are presenting data from the study on the various types of sales promotion.

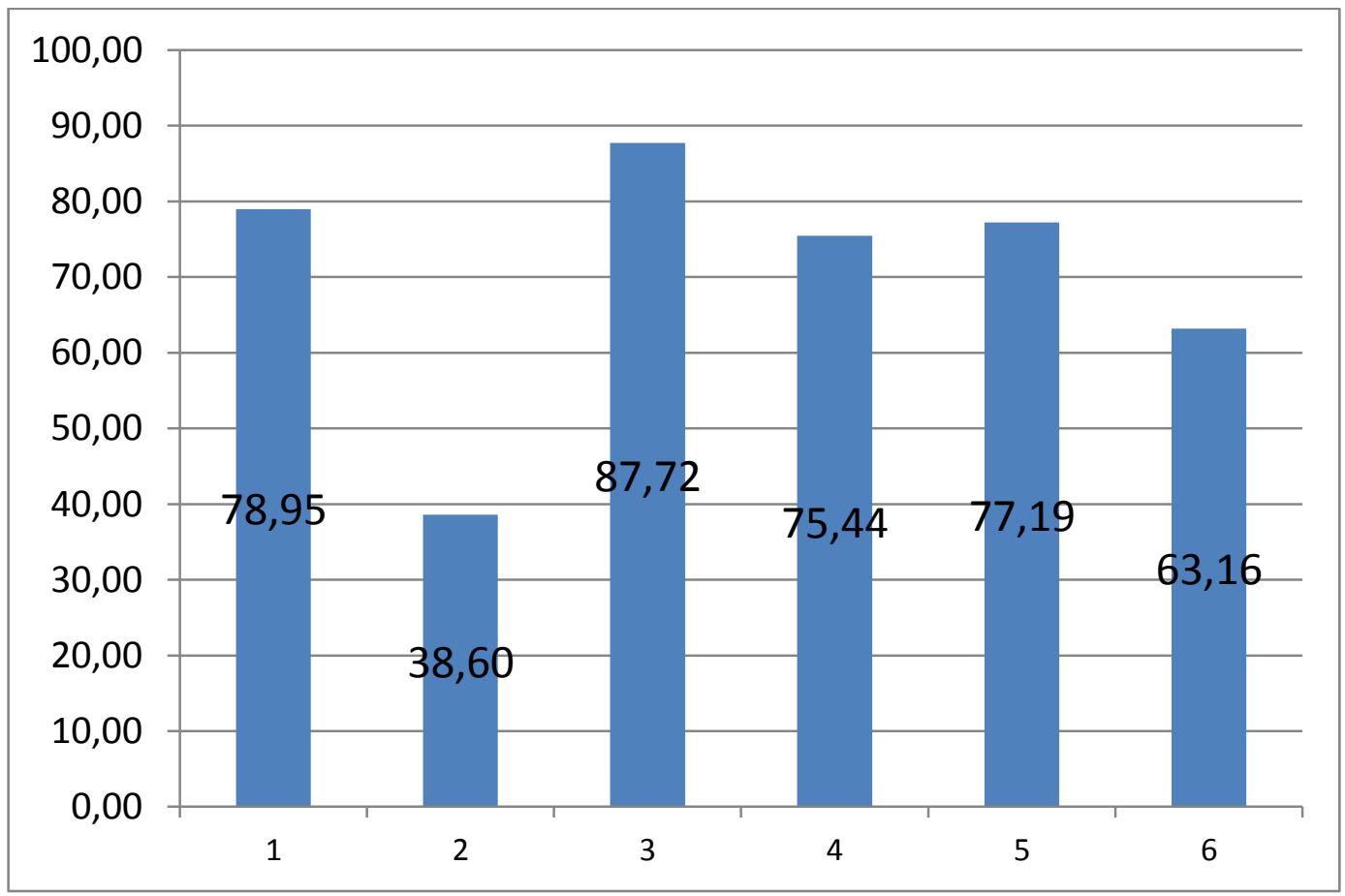

Figure 1. The level of awareness of the various sales promotion instruments

Legend: 1. Sampling, 2.Coupons, 3.Premiums - goods in a package, 4.Discounts, 5. Extras / additional product, quantity /, 6.Contests, lotteries, games

The average degree of cognition among respondents is over $70 \%$, and this is a clear indicator that they are widely used in the practice of today's sales promotion techniques .

The most recognizable techniques are the socalled premium or a sale of two different products in a package of $87.7 \%$. The following three instruments are very close to each other: distribution of samples - 79\%, goods in extras / additional product, quantity $/-77.2 \%$, and a discounts $-75.4 \%$. Last but not least, the use of coupons remains $38.6 \%$.

Let us also pay attention to the differences between the sexes - men and women. 
GENCHEV E., et al.

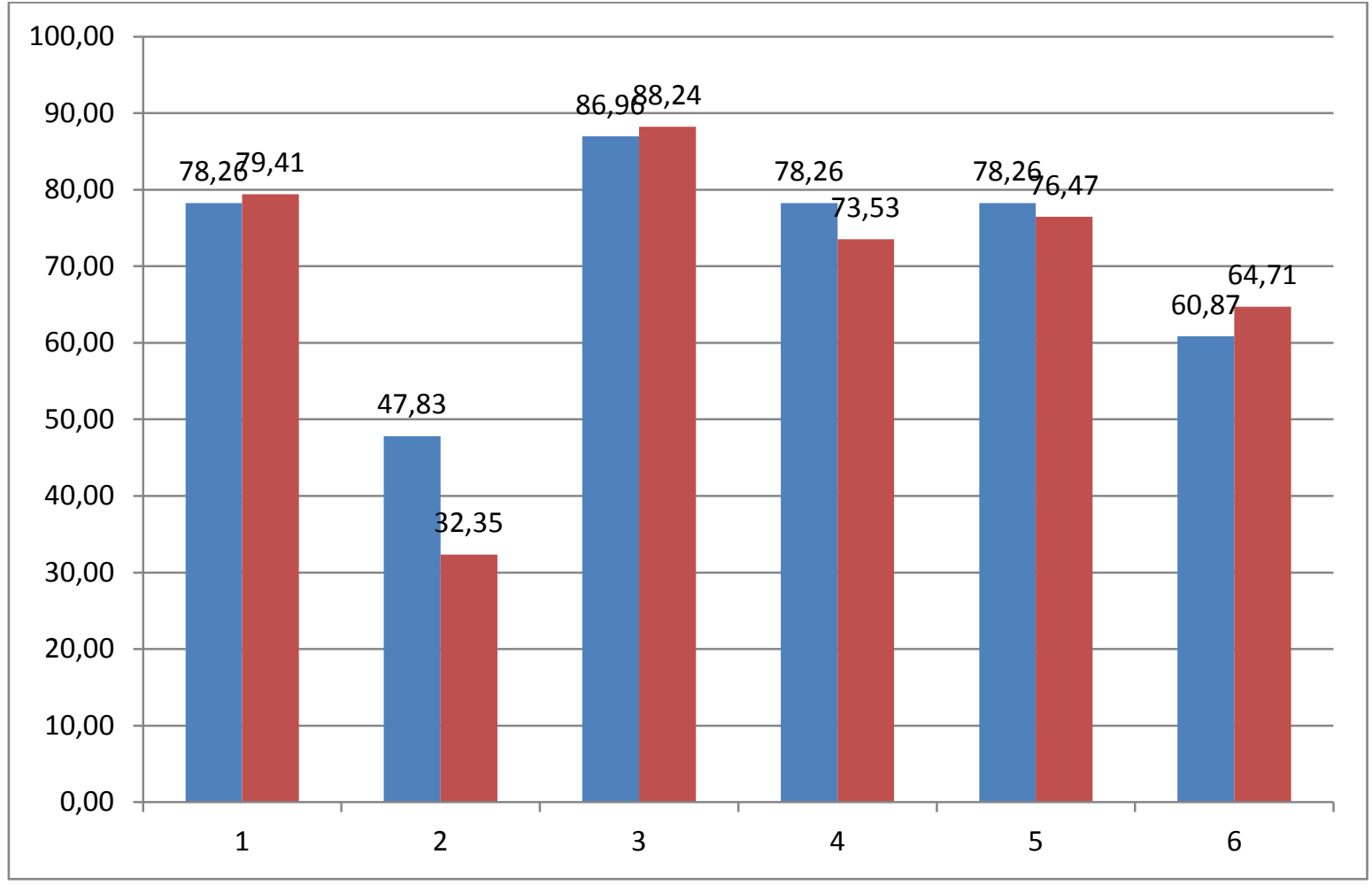

Figure 2. The use of sales promotion techniques by sex

Legend: 2. Samples, 2.Coupons, 3.Premiums - goods in a package, 4.Discounts, 5. Extras / additional product, quantity /, 6.Contests, lotteries, games

The differences in almost all techniques of promotion between the two sexes are extremely small. The only difference that deserves attention is when using coupons. When we wish to know whether the means of two groups (one independent variable (e.g., gender) with two levels (e.g., males and females) differ, a $t$ test is appropriate. In order to calculate a $t$ test, we need to know the mean, standard deviation, and the number of subjects in each of the two groups. In this case:

(H0) - will claim that there is no statistically significant difference in the use of coupons in both genders. Although a certain difference can be observed in the samples, it is random and can not be summed up for general populations.

(H1) -will claim that there is a statistically significant difference between the two genders and can be summed up for the general population.

We use online internet calculators [6]. Let's see the test result:

$\mathrm{Z}$-value is $1.18, \mathrm{p}$-value -0.238 . Since $\mathrm{p}$-value -0.238 is higher than 0.05 , there is no reason to reject the zero hypothesis.

Conclusion: the gender does not affect the degree of awareness of all analyzed sales promotion tools.

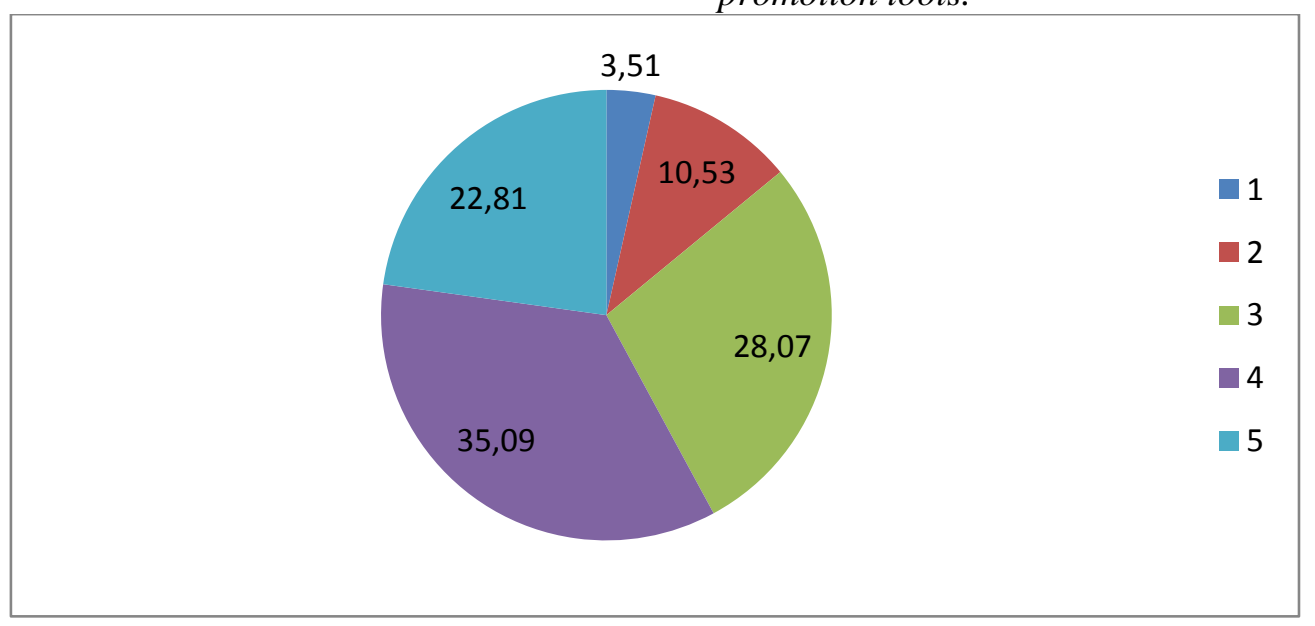

Figure 3 Frequency of use of sales promotion

Legend: 5-Daily, 4-Several times a week, 3-Several times a month, 2-Less than once a month and 1Never 
GENCHEV E., et al.

Obviously, this communication tool is well known to the Bulgarian consumer and he regularly takes advantage of its benefits. The total percentage of users who use it daily or several times a week is nearly 58\%. Only 3.5\% of the sample responded that they did not use the promotion for their purchases.
To determine whether gender and age influence on the frequency of use, we can apply ANOVA. In the model below, recall that the dependent variable (frequency of use) is quantitative as in regression, but the independent variable (gender/age) is now qualitative. For the analysis of the information we use the SPSS statistical software.

Table 1. ANOVA Influence of gender on use of sales promotion

\begin{tabular}{|c|c|c|c|c|c|}
\hline & $\begin{array}{c}\text { Sum of } \\
\text { Squares }\end{array}$ & df & Mean Square & F & Sig. \\
\hline $\begin{array}{c}\text { Between } \\
\text { Groups }\end{array}$ & 1,493 & 1 & 1,493 & 1,330 &, 254 \\
\hline Within Groups & 61,770 & 55 & 1,123 & & \\
\hline Total & 63,263 & & & & \\
\hline
\end{tabular}

The frequency of use of sales promotion per mount for women is stronger than for men 3.76 vs. 3.46 or about 10\% more but the difference is not statistically significant because:
Since p-value - 0.254 is higher than 0.05 there is no reason to reject the zero hypothesis.

Conclusion: Gender does not influence the frequency of use of sales promotion.

Table 2. ANOVA Influence of age on use of sales promotion

\begin{tabular}{|c|c|c|c|c|c|}
\hline & $\begin{array}{c}\text { Sum of } \\
\text { Squares }\end{array}$ & df & Mean Square & F & Sig. \\
\hline $\begin{array}{c}\text { Between } \\
\text { Groups }\end{array}$ & 8,771 & 4 & 2,193 & 2,093 &, 095 \\
\hline Within Groups & 54,492 & 52 & 1,048 & & \\
\hline Total & 63,263 & 56 & & & \\
\hline
\end{tabular}

The frequency of use of sales promotion among respondents aged 25-34 is the highest, and those aged 18-24 are the lowest. Here, the influence of age factor is much more pronounced because the level of statistical significance is 0.095 or at the theoretical level of 0.10 we can accept the alternative hypothesis that age affects the frequency of use of sales promotion.

Impact of sales promotion

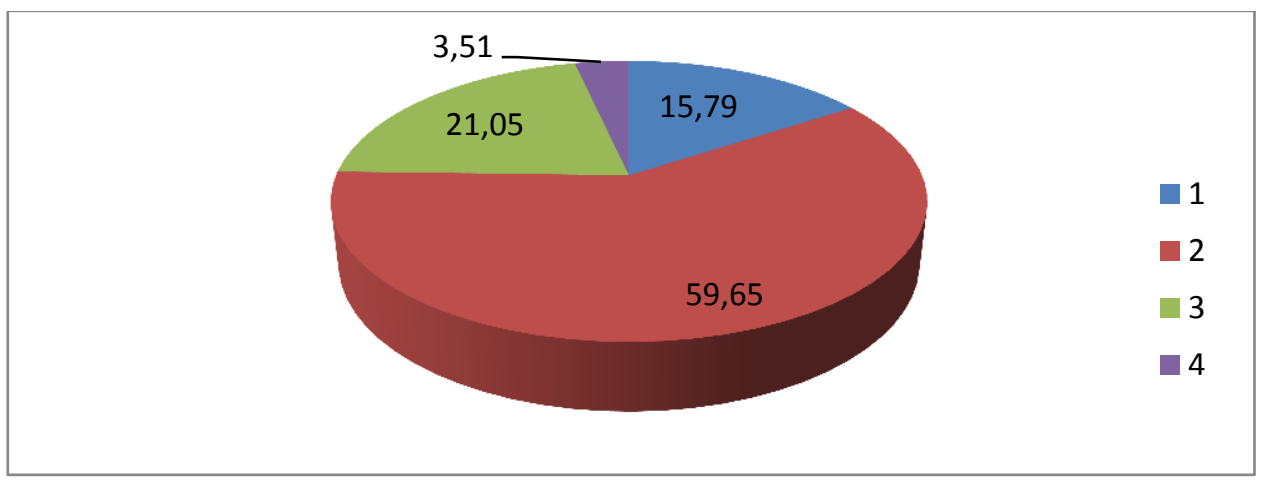

Figure 4. What is the probability of buying a product that uses sales promotion?

Legend: 4- Maybe I will not buy, 3- I will definitely buy, 2-I will probably buy, 1 -not Yes or no

From the responses mentioned above, it became clear that all sales promotion types and techniques have a good efficiency for consumers, as $21 \%$ would certainly buy, and more than $59 \%$ of respondents would probably benefit from a promotional product. Thus, the cumulative effect of the two groups responded positively to over $80 \%$.

Information channels and appropriate product groups for different types of sales promotion. Another goal of the study was to determine the impact of different promotional techniques on 
consumer buying behaviour and to show organisations where to use these techniques to increase their sales. Different types of communication channels are used for sales promotion. The Internet is defined as the most commonly used instrument of reaching information about various promotional activities for the consumer with $82.5 \%$ and promotional brochures with $77.2 \%$. Third posision is for $\mathrm{TV}$ as a communications channel, and then are newspapers, magazines and radio.

An efficiency of various sales promotions depending on the type of product.
To determine the most effective sales promotion type, we have classified products according to their durability and tangibility as follows:

- Non-durable products - tangible goods that are consumed once, are often purchased as food and cosmetics.

- Durable products - tangible goods that are purchased less frequently because they are used for a long time. They require warranty, service and additional services from the seller such as electrical appliances, clothing.

- Services - Activities or benefits that do not lead to the acquisition of property, Intangible goods such as tourism, education and transport.

Table 3. Efficiency of the promotional tool depending on the type of product, according to users

\begin{tabular}{|l|l|l|l|}
\hline & Non-durable products & Durable products & Services \\
\hline Samples & 70,2 & 5,3 & 3,5 \\
\hline Coupons & 29,8 & 10,5 & 12,3 \\
\hline Prices reductions & 19,3 & 61,4 & 17,5 \\
\hline Premium products & 8,8 & 24,6 & 21,1 \\
\hline Bonus products & 52,6 & 17,5 & 3,5 \\
\hline $\begin{array}{l}\text { Contests, lotteries, } \\
\text { games }\end{array}$ & 14 & 15,8 & 31,6 \\
\hline
\end{tabular}

- For non-durable products, the two bestperforming tools with a high level of support are respectively $-70.2 \%$ and additional bonuses of $52.6 \%$.

- For durable products, the best consumer perceived value is the $61.4 \%$ reduction in short-term prices and the use of so-called commodity premiums; if buying a product as washing machine we get another product as detergent and etc.

- For services, we have the evenest distribution of the different funds, but the biggest share is the use of games, competitions $-31.6 \%$.

\section{CONCLUSION}

The overall conclusion of this study is that we find a positive attitude from clients towards all promotional activities techniques. The study confirms that sales promotion is an effective tool and has a positive direct impact on the client's intention to buy.. If an organisation effectively selects its sales promotion techniques, it will not only increase its orders, but it will also increase the sales efficiency of the entire organisation.

From the responses mentioned above, it became clear that all types and instruments of sales promotion have a good efficiency for consumers, as $21 \%$ would certainly buy, and more than $59 \%$ of respondents would probably benefit from a promotional product.
The most commonly used technique for reaching information about various promotional activities is the Internet with $82.5 \%$ and promotional brochures with $77.2 \%$. Different instruments of sales promotion also have a different degree of influence on consumers. It's depending on the type of product in which they are used.

\section{REFERENCES}

1. Akhter, Sameen, et al. "The impact of retail shoes sales promotional activities on ladies' purchase intentions." Journal of Public Administration and Governance 4.2 (2014): 166-178.

2. Kotler P, Keller K. 2006. Marketing Management (12th edn). Pearson Education: Upper Saddle River, NJ, p. 294

3. Palmer, Adrian Introduction in marketing Theory and Practice, second edition, Oxford University Press Inc., 2004

4. Gilbert, D. C., and N. Jackaria. "The efficacy of sales promotions in UK supermarkets: a consumer view." International Journal of Retail \& Distribution Management 30.6 (2002): 315322.

5. Steenkamp, Jan-Benedict EM, et al. "Competitive reactions to advertising and promotion attacks." Marketing science 24.1 (2005): 35-54.

6. http://www.socscistatistics.com/tests/ztest/ Default2.aspx 